(Journal of Civil Engineering, Building and Transportation)

\title{
Analisa Perencanaan Jalur Sepeda Motor Pada Kawasan Tertib Lalu Lintas Di Kota Medan
}

\section{Analysis Of Motorcycle Lane Planning In The Orderly Areas Of Traffic In The City Of Medan}

\author{
Muhammad Ilham Ashari'1), Kamaluddin Lubisi), Nuril Mahda Rangkuti 1) \\ 1)Program Studi Teknik Sipil, Fakultas Teknik \\ Universitas Medan Area, Indonesia \\ e-mail : ilhamashari17@gmail.com \\ Diterima: April 2019; Disetujui: Mei 2019; Dipublish: Mei 2019
}

\begin{abstract}
Abstrak
Penelitian ini dilakukan untuk mengetahui bagaimana kondisi kinerja ruas jalan tertib lalu lintas terutama jalan Pangeran Diponegoro sebagai subjek penelitian saat ini dikaitkan dengan perencanaan lajur khusus sepeda motor. Penelitian ini menggunakan metode survey lapangan dengan melakukan pengamatan secara langsung di ruas jalan Pangeran Diponegoro dengan menyebarkan surveyor pada titik-titik tertentu guna memudahkan dalam pencatatan sehingga diperoleh data pengamatan yang valid. Pengamatan langsung dilakukan dengan pencatatan secara manual data jumlah kendaraan yang melewati ruas jalan Pangeran Diponegoro, jenis kendaraan, serta geometric ruas jalan tersebut. Analisis penelitian menggunakan microsoft exel. Hasil dari identifikasi dan penelitian lapangan yang telah di analisis diketahui tingkat pelayanan dari ruas jalan Pangeran Diponegoro pada segmen 1 adalah nilai $\mathrm{V} / \mathrm{C}$ rasio tahun 2017 sebesar 0.69 dengan tingkat pelayanan $\mathrm{C}$, pada tahun 2020 menjadi 0.91 dengan tingkat pelayanan E (meningkat 0.22 ), dan diperhitungkan dan pada tahun 2021 nilai $\mathrm{V} / \mathrm{C}$ rasio menjadi 0.99 dengan tingkat pelayanan E (meningkat 0.08). Sedangkan segmen 2 adalah Nilai V/C rasio tahun 2017 sebesar 0.51 dengan tingkat pelayanan C, pada tahun 2020 menjadi 0.68 dengan tingkat pelayanan C (meningkat 0.17 ), dan diperhitungkan dan pada tahun 2021 nilai $\mathrm{V} / \mathrm{C}$ rasio menjadi 0.74 dengan tingkat pelayanan D (meningkat 0.06).Maka diharapkan pembuatan lajur khusus sepeda motor harus segera direalisasi untuk menekan peningkatan nilai $\mathrm{V} / \mathrm{C}$ dan dapat membuat kinerja ruas jalan khususnya jalan Pangeran Diponegoro terus menurun atau mengalami kemacetan serius pada tahuntahun yang akan datang.
\end{abstract}

Kata Kunci : Volume lalu lintas, Kinerja ruas jalan, lajur khusus

\begin{abstract}
This research was conducted to find out how the performance condition of road traffic order especially Pangeran Diponegoro as the subject of research is now related to the planning of special lane of motorcycle. This research uses field survey method by conducting direct observation on Pangeran Diponegoro prison road by spreading surveyors at certain points in order to facilitate the recording so as to obtain valid observation data. Direct observation is done by manually recording the data of the number Pangeran Diponegoro of vehicles passing the Pangeran Diponegoro prison, the type of vehicle, and the geometric of the road. Analysis of research using microsoft exel. The result of identification and field research that has been analyzed is known service level of Pangeran Diponegoro prison segment in segment 1 is value of $\mathrm{V} / \mathrm{C}$ ratio year 2017 equal to 0.69 with service level $C$, in 2020 becomes 0.91 with service level $E$ (increase 0.22) and calculated and in 2021 the value of V/C ratio to 0.99 with service level E (increased 0.08). While the segment 2 is the value of $\mathrm{V} / \mathrm{C}$ ratio of 2017 of 0.51 with service level $C$, in 2020 to 0.68 with service level $C$ (increased 0.17), and calculated and in 2021 the value of V/C ratio to 0.74 with service level $D$ (increased 0.06). It is hoped that the manufacture of special lane of motorcycle must be realized to suppress the increase of $V / C$ value and can make the performance of road segment especially Pangeran Diponegoro road decreasing or experiencing serious congestion in the years to come.
\end{abstract}

Key Words: Traffic volume, Road performance, special lane

How to Cite: Ashari, M, I, Nuril Mahda, R dan Kamaluddin, L (2019), Analisa Perencanaan Jalur Sepeda Motor Pada Kawasan Tertib Lalu Lintas Di Kota Medan. JCEBT (Journal of Civil Engineering, Building and Transportation). 3 (1): 27-39 


\section{PENDAHULUAN}

Kota Medan merupakan daerah pusat perekonomian sehingga secara langsung menarik lalu lintas dari pinggiran kota maupun dari luar kota yang mayoritas menggunakan sepeda motor sebagai alat transportasinya. Jl. Pangeran Diponegoro merupakan salah satu jalan tertib lalu lintas di kota medan yang banyak terdapat hotel, perkantoran dan memungkinkan masyarakat melakukan awal dan akhir pergerakan dari aktivitas mereka pada daerah ruas jalan ini. Selain itu juga terdapat banyak persimpangan yang cukup mengganggu arus lalu lintas pada jalan utama (Jl. Pangeran Diponegoro), serta terjadinya percampuran berbagai jenis kendaraan sehingga memberikan dampak negative seperti berhentinya kendaraan yang dilakukan oleh angkutan umum yang berhenti sembarangan atau perilaku pengendara sepeda motor yang umumnya berpindahpindah jalur sehingga mengganggu pengguna kendaraan lainnya dan meningkatkan resiko terjadinya kecelakaan lalu lintas. Salah satu solusi untuk mengatasi permasalahan di atas adalah dengan diterapkan suatu jalur khusus untuk masing-masing kendaraan.

Penelitian ini bermaksud dan bertujuan untuk

- Adapun maksud dari penelitian ini adalah untuk menganalisa kinerja ruas jalan dan perencanaan jalur sepeda motor pada kawasan tertib lalu lintas pada Jl. Pangeran Diponegoro.

- Penelitian ini bertujuan untuk meningkatkan kinerja ruas jalan serta perencanaan penetapan jalur khusus sepeda motor pada kawasan tertib lalu lintas.

\section{* Umum}

Semakin tingginya pengguna kendaraan pribadi baik kendaraan roda dua maupun roda empat mengakibatkan volume lalu lintas meningkat khususnya pada saat jam puncak baik pagi, siang dan sore hari dimana terjadi pergerakan yang bersamaan dari bangkitan perjalanan menuju tujuan atau tarikan perjalanan. Dalam bukunya Tamin (2000) menjelaskan penggunaan kendaraan pribadi meningkatkan kesempatan seseorang untuk bekerja, memperoleh didikan, berbelanja, rekreasi maupun melakukan aktivitas sosial lainnya. Pada umumnya peningkatan pemilikan kendaraan pribadi merupakan cerminan hasil interaksi antara peningkatan taraf hidup dan kebutuhan mobilitas penduduk di daerah perkotaan.

\section{Ruas Jalan}

Ruas jalan adalah bagian atau penggal jalan di antara dua simpul/persimpangan sebidang atau tidak sebidang baik yang dilengkapi dengan alat pemberi syarat lalu lintas ataupun tidak.

* Geometrik Ruas Jalan

1. Tipe Jalan

Berbagai tipe jalan yang akan menunjukan kinerja berbeda pada pembebanan lalu lintas tertentu, misalnya jalan terbagi, tak terbagi dan jalan satu arah.

2. Lebar Jalur Lalu Lintas

Kecepatan arus bebas dan kapasitas meningkat dengan pertambahan lebar jalur lalu lintas.

3. Jalur lalu lintas

Jalur lalu lintas (traveled way = carriage way) adalah keseluruhan bagian perkerasan jalan yang diperuntukan untuk lalau lintas kendaraan.

4. Kereb

Kereb adalah penonjolan atau peninggian tepi perkerasan atau bahu jalan, yang terutama dimaksudkan untuk keperluan-keperluan drainase, mencegah ketegasan tepi perkerasan.

- Kereb peninggi (mountable curb)

- Kereb penghalang (barrier curb)

- Kereb berparit (gutter curb)

- Kereb penghalang berparit (barrier gutter curb)

5. Saluran Samping

Saluran samping terutama berguna untuk:

- Mengalirkan air dari permukaan jalan ataupun dari bagian luar jalan

- Menjaga supaya konstruksi jalan selalu berada dalam keadaan kering tidak terendam air.

\section{* Kinerja Lalu Lintas}


Dalam penelitian ini akan lebih fokus dengan indikator berupa tingkat pelayanan jalan (level of service), waktu, jarak dan kecepatan rata-rata perjalanan. Tingkat pelayanan jalan adalah suatu ukuran yang dapat digunakan untuk mengetahui kualitas suatu ruas jalan tertentu dalam melayani arus lalu lintas yang melewatinya. Tingkat pelayanan ditemukan berdasarkan nilai kuantitatif seperti VCR, kecepatan perjalanan dan berdasarkan nilai kualitatif seperti kebebasan pengemudi dalam bergerak/memilih kecepatan, derajat hambatan lalu lintas serta kenyamanan (Morlock, 1988). Untuk mengetahui kinerja jalan dapat diketahui dari tingkat pelayanan dari jalan yang ada. Berdasarkan MKJI 1997, ditetapkan bahwa untuk kondisi normal nilai $\mathrm{V} / \mathrm{C}>0,75$ yang terjadi pada suatu segmen jalan dinyatakan bermasalah. Masalah dimaksud adalah keterbatasan kapasitas atau keterbatasan volume akibat gangguan pergerakan di sepanjang ruas jalan yang ditinjau. Karakteristik tingkat pelayanan jalan dapat dijelaskan pada Tabel 1.

Tabel 1. Tingkat Pelayanan Jalan

\begin{tabular}{clc}
\hline $\begin{array}{c}\text { Tingkat } \\
\text { Pelayanan }\end{array}$ & \multicolumn{1}{c}{ Karakteristik - Karakteristik } & $\begin{array}{c}\text { Batas Lingkup } \\
\text { V/C }\end{array}$ \\
\hline A & $\begin{array}{l}\text { Kondisi arus lalu lintas dengan kecepatan } \\
\text { tinggi dari volume lalu lintas rendah. } \\
\text { Pengemudi dapat memilih kecepatan yang } \\
\text { diinginkan tanpa hambatan. }\end{array}$ & $0,00-0,19$ \\
& $\begin{array}{l}\text { Dalam zona arus lalu lintas stabil. } \\
\text { Pengemudi memiliki kebebasan yang cukup } \\
\text { untuk memilih kecepatannya. }\end{array}$ & $0,20-0,44$ \\
\hline B & $\begin{array}{l}\text { Dalam zona arus lalu lintas stabil. Pengemudi } \\
\text { dibatasi dalam memilih kecepatannya. }\end{array}$ & $0,45-0,74$ \\
\hline C & $\begin{array}{l}\text { Mendekati arus tidak stabil dimanahampir } \\
\text { seluruh pengemudi akan dibatasi. Volume } \\
\text { pelayanan berkaitan dengan kapasitas yang } \\
\text { dapat ditolerir. }\end{array}$ & $0,75-0,85$ \\
\hline $\mathrm{E}$ & $\begin{array}{l}\text { Volume lalu lintas mendekati atau berada } \\
\text { pada kapasitasnya. Arus adalah tidak stabil } \\
\text { dengan kondisi yang sering berhenti. }\end{array}$ & $0,85-1,00$ \\
\hline & $\begin{array}{l}\text { Arus yang dipaksakan atau macet pada } \\
\text { kecepatan-kecepatan yang rendah. Antrian } \\
\text { yang panjang dan terjadi hambatan- } \\
\text { hambatan yang besar. }\end{array}$ & $\begin{array}{c}\text { Lebih besar } \\
\text { dari 1,00 }\end{array}$ \\
\hline F & Sumber : Manual Kapasitas Jalan Indonesia (1997)
\end{tabular}

\section{METODE PENELITIAN}

Penelitian ini dilaksanakan dalam waktu 4 hari yaitu: senin, selasa, rabu, dan sabtu dimana dalam waktu itu telah mewakili waktu terpadat dalam seminggu. Waktu penelitian dimulai jam 07.00 - 18.00 WIB dengan asumsi pada waktu tersebut adalah waktu puncak terjadinya arus pergerakan Sepeda motor di Jl. Pangeran Diponegoro. (Direktorat Jenderal Perhubungan Darat: "Panduan Pengumpulan Data Angkutan Umum Perkotaan")

Data yang akan dikumpulkan yaitu:

a. Data Primer
Data primer merupakan data yang diperoleh secara langsung melalui survei lapangan

b. Data Sekunder

Data sekunder merupakan data yang diperoleh dari instansi pemerintah yang terkait

Langkah-langkah survei yang dilakukan :

1. Mendistribusikan secara jelas surveyor pada titik - titik lokasi pengamatan.

2. Mempersiapkan alat-alat tulis berupa pulpen/pensil dan kertas, lalu menyamakan arloji ataupun alat pencatat waktu yang sejenis. Selanjutnya proses pencatatan data 
3. Setiap kendaraan yang melewati Jl. Pangeran Diponegoro dicatat oleh surveyor berupa jumlah sepeda motor, waktu pada saat lewat, Bila tidak memungkinkan mencatat semua variable diatas karena frekuensi kendaraan yang padat maka diutamakan mencatat jumlah dan jenis sepeda motor.

4. Setelah pengambilan data selesai dan dilakukan pengumpulan, diatur sesuai tanggal dan tempat. Langkah-langkah analisis data sebagai berikut :

a. Menentukan geometrik ruas jalan yang diteliti.

b. Menentukan jumlah lajur sepeda motor pada jalan yang dilakukan penelitian.

c. Menghitung volume kendaraan dalam 1 hari.

d. Menghitung pertumbuhan kendaraan.

e. Menghitung kinerja ruas jalan

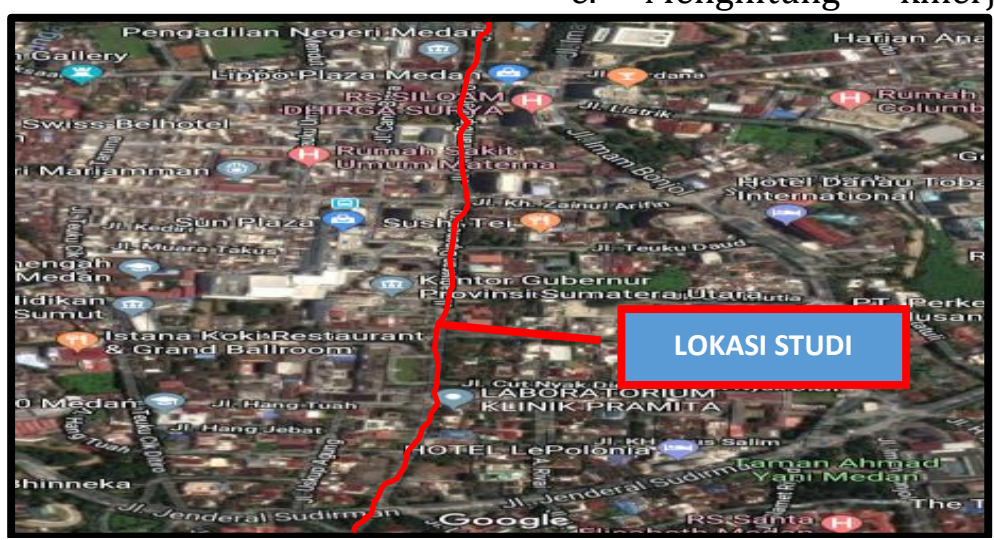

Gambar 1. Peta Lokasi Penelitian

Sumber : Goggle Map

\section{HASIL DAN PEMBAHASAN}

* Gambaran Umum

Mengacu dari Manual Kapasitas Jalan Indonesia (MKJI) 1997 Jalan Perkotaan, evaluasi kinerja pada ruas Jl. Pangeran Diponegoro dilakukan untuk:

1. Mengetahui Indeks Tingkat Pelayanan (ITP) ruas Jl. Pangeran Diponegoro pada saat ini.

2. Menentukan kelayakan perencanaan jalur khusus sepeda motor agar dapat mengurai kemacetan dan mengurangi tingkat kecelakaan yang saat ini terjadi.

\section{* Lokasi Studi}

Lokasi Kegiatan penelitian ini dilakukan di Kawasan Tertib Lalu lintas (KTL) pada ruas Jl. Pangeran Diponegoro kota Medan Sumatera Utara, di mulai dari simpang Jl. Sudirman sampai dengan persimpangan Jl. Kejaksaan kota Medan, yang dibagi menjadi dua segmen yaitu dimulai dari persimpangan Jl. Sudirman sampai dengan persimpangan Jl. Zainal Arifin merupakan segmen 1 dan segmen 2 dimulai dari persimpangan Jl. Zainal Arifin sampai dengan persimpangan Jl. Kejaksaan kota Medan. Lokasi studi kegiatan tersebut dapat dilihat pada gambar berikut, 


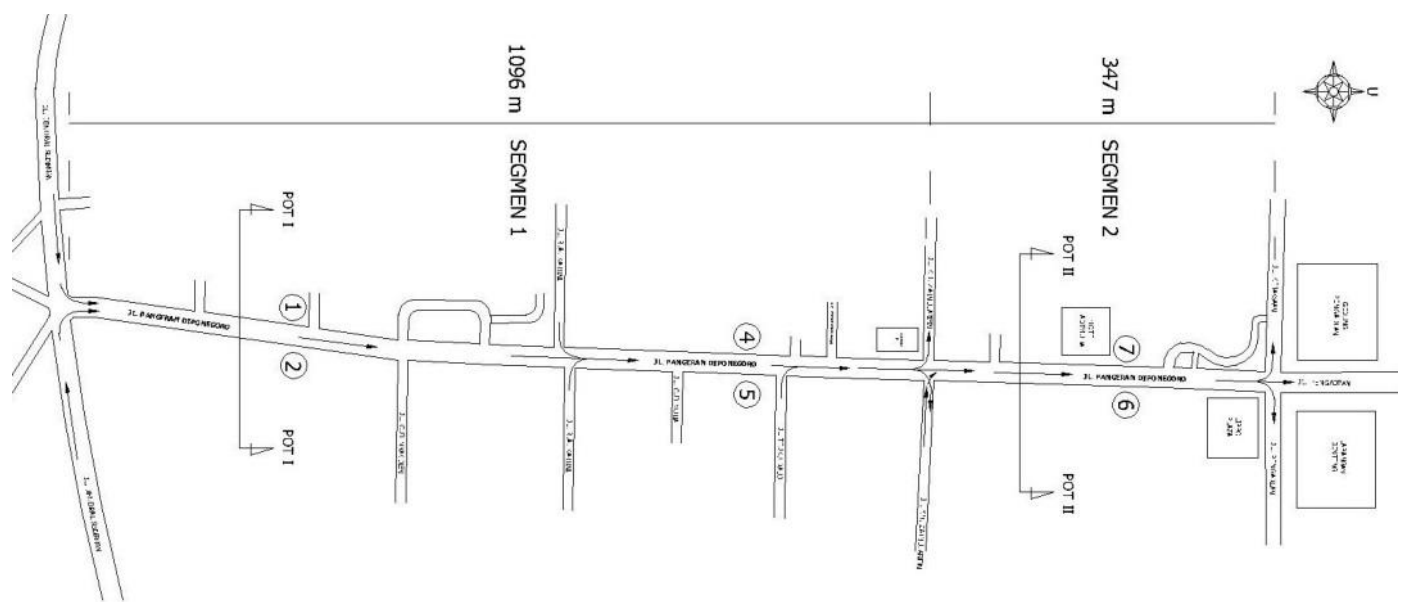

LAYOUT JL. PANGERAN DIPONEGORO

Gambar 2. Sketsa Peta Lokasi Penelitian Sumber : Hasil Survey

Dari hasil pengukuran dilapangan di ketahui bahwa total jarak lokasi penelitian adalah $1.443 \mathrm{Km}$ yang terbagi atas 2 segmen yaitu : jarak pada segmen 1 sebesar $1,096 \mathrm{Km}$ dan jarak pada segmen 2 sebesar $0,347 \mathrm{Km}$, tipe jalan $4 / 1$ tanpa median atau 4 lajur satu arah.
Geometrik Ruas Jalan

Data geometrik ruas Jl. Pangeran Diponegoro dikumpulkan melalu pengukuran langsung dilapangan dengan cara pengukuran daerah milik jalan yang didalamnya termasuk trotoar, data geometrik hasil pengukuran lapangan seperti berikut,

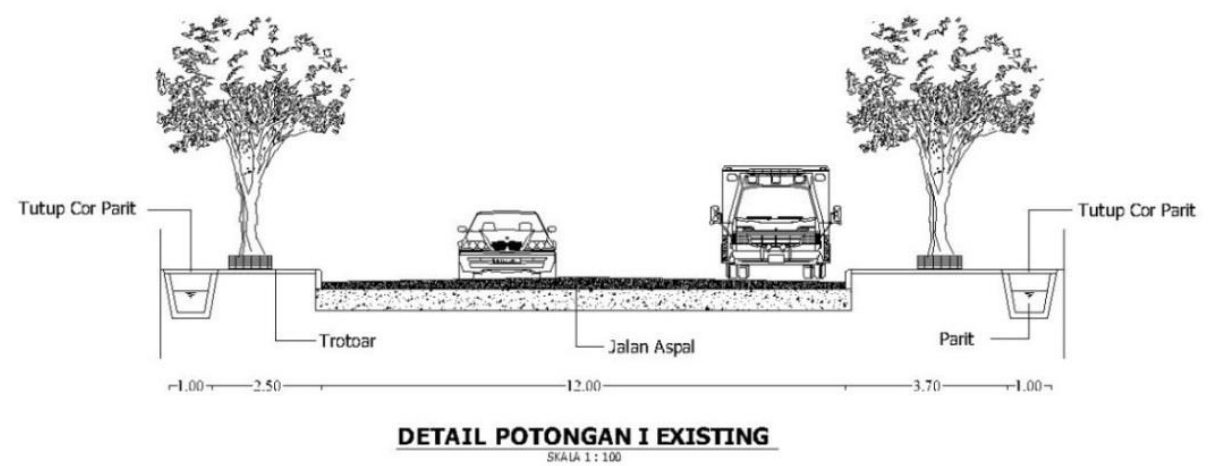

Gambar 3. Detail Potongan I Sumber : Hasil Survey

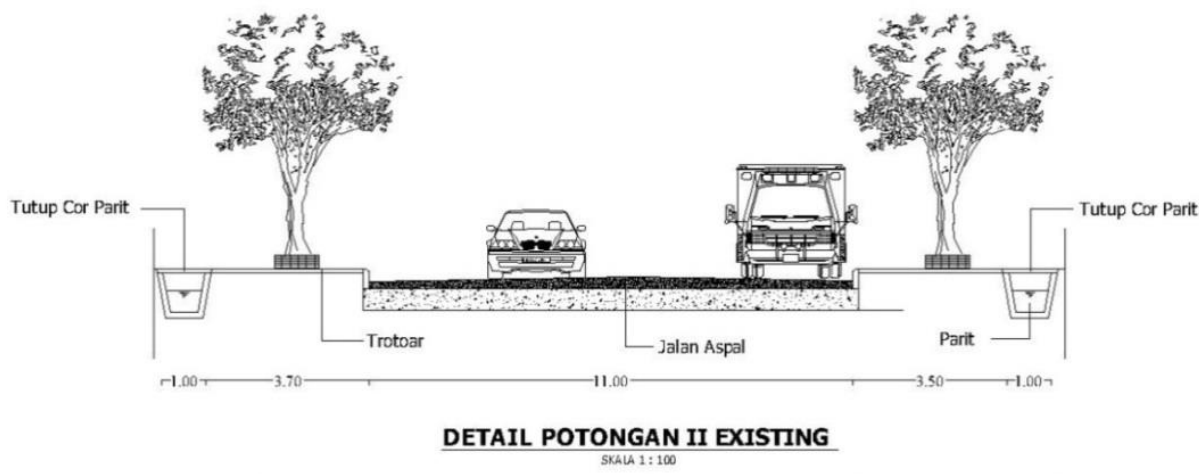

Gambar 4. Detail Potongan II 
Sumber : Hasil Survey

Tipe ruas jalan 4 lajur 1 arah dengan kelas hambatan samping rendah, kondisi kiri kanan jalan terdiri dari perkantoran pemerintah, perkantoran swasta, perhotelan, rumah Ibadah dan terdapat juga plaza namun bangunan kiri kanan jalan memiliki parkir area sehingga tidak memanfaatkan ruas jalan menjadi tempat parkir.

* Volume lalu lintas

Variasi lalulintas biasanya berulang ( cyclical ) mungkin jam-an, harian, atau musiman. Pemilihan waktu survei yang pantas tergantung dari tujuan survei. Untuk menggambarkan kondisi lalulintas pada jam puncak, maka survei dilakukan pada jam-jam sibuk seperti pagi hari yang dimulai pada pukul 07.00 wib s/d 09.00 wib, pada siang hari dilakukan pada pukul 11.00 wib s/d 13.00 wib,dan pada sore hari dilakukan pada pukul 16.00 wib s/d 18.00 wib.
Dari hasil survei lapangan terhadap arus lalu lintas, diperoleh waktu puncak arus lalu lintas terjadi pada hari senin, 18 Desember 2017 pukul 17.00 - 18.00 wib sore hari segmen 1 dan segmen 2 .

Sebelum dilakukan analisa data maka terlebih dahulu data arus lalu lintas hasil survey yang satuannya masih kendaraan perjam terlebih dahulu di kalibrasikan menjadi smp per-jam dengan cara mengalikan angka ekivalen mobil penumpang (emp) dengan data volume lalu lintas yang satuannya masih kendaraan/jam agar menjadi smp/jam. Adapun nilai ekivalen mobil penumpang (emp) untuk kendaraan ringan sebesar 1 dan nilai emp kendaraan berat sebesar 1,5 dan nilai emp sepeda motor sebesar 0,4.

Data Volume arus lalu lintas pada waktu puncak hasi pengumpulan langsung dilapangan ( survey ) seperti berikut,

Tabel 2. Data Volume Lalu Lintas Ruas Jl. Pangeran Diponegoro Saat Jam Puncak

\begin{tabular}{|c|c|c|c|c|c|c|c|c|c|c|}
\hline \multirow{2}{*}{ No. } & \multirow[t]{2}{*}{ Waktu } & \multirow[t]{2}{*}{ Segmen } & \multicolumn{2}{|c|}{$\begin{array}{l}\text { Jumlah Kend. } \\
\text { Pribadi }\end{array}$} & \multicolumn{2}{|c|}{$\begin{array}{c}\text { Jumlah Angk. } \\
\text { Umum }\end{array}$} & \multicolumn{2}{|c|}{$\begin{array}{l}\text { Jumlah Sepeda } \\
\text { Motor }\end{array}$} & \multicolumn{2}{|c|}{ Total Kend. Bermotor } \\
\hline & & & (kend/j) & $(\mathrm{smp} / \mathrm{j})$ & (kend/j) & $(\mathrm{smp} / \mathrm{j})$ & (kend/j) & $(\mathrm{smp} / \mathrm{j})$ & (kend/j) & $(\mathrm{smp} / \mathrm{j})$ \\
\hline 1 & $07.00-08.00$ & 1 & 1403 & 1402.5 & 216 & 215.9 & 2851 & 1140.36 & 4469 & 2758.76 \\
\hline 2 & 08.01-09.00 & 1 & 1416 & 1416.1 & 235 & 234.6 & 2887 & 1154.64 & 4537 & 2805.34 \\
\hline 3 & $11.00-12.00$ & 1 & 1341 & 1341.3 & 213 & 212.5 & 2817 & 1126.76 & 4371 & 2680.56 \\
\hline 4 & $12.01-13.00$ & 1 & 1369 & 1368.5 & 228 & 227.8 & 2837 & 1134.92 & 4434 & 2731.22 \\
\hline 5 & $16.00-17.00$ & 1 & 1435 & 1434.8 & 231 & 231.2 & 2893 & 1157.36 & 4559 & 2823.36 \\
\hline 6 & $17.01-18.00$ & 1 & 1454 & 1453.5 & 241 & 241.4 & 2904 & 1161.44 & 4599 & 2856.34 \\
\hline 7 & $07.00-08.00$ & 2 & 1034 & 1033.6 & 167 & 167 & 2134 & 853.4 & 3334 & 2053.6 \\
\hline 8 & $08.01-09.00$ & 2 & 1054 & 1054 & 177 & 176.8 & 2147 & 858.84 & 3378 & 2089.64 \\
\hline 9 & $11.00-12.00$ & 2 & 1000 & 999.6 & 162 & 161.5 & 2103 & 841.16 & 3264 & 2002.26 \\
\hline 10 & $12.01-13.00$ & 2 & 1012 & 1011.5 & 173 & 173.4 & 2117 & 846.6 & 3301 & 2031.50 \\
\hline 11 & $16.00-17.00$ & 2 & 1068 & 1067.6 & 182 & 181.9 & 2161 & 864.28 & 3410 & 2113.78 \\
\hline 12 & $17.01-18.00$ & 2 & 1080 & 1079.5 & 179 & 178.5 & 2176 & 870.40 & 3434 & 2128.40 \\
\hline
\end{tabular}

Dari data hasil survey pada table 2. di atas diketahui bahwa volume lalu lintas maksimum terjadi pada hari senin, untuk segmen 1 sebesar 2856,34 smp/jam dan segmen 2 sebesar 2128,4 smp/jam. Data arus lalu lintas jam puncak inilah nantinya yang akan digunakan sebagai data volume lalu lintas pada saat perhitungan dengan menggunakan bantuan Manual Kapasitas Jalan Indonesia (MKJI).

\section{Kinerja Lalu Lintas Eksisting.}

Ruas jalan yang dinilai unjuk kerjanya adalah ruas Jl. Pangeran Diponegoro yang 
berada di wilayah daerah Kawasan Tertib Lalu Lintas (KTL) Kota Medan. Ruas Jl. Pangeran Diponegoro dibagi menjadi dua segmen yaitu segmen 1 ( Ruas Jl. dipenegoro 1) dan segmen 2 ( Ruas Jl. Dipenegoro 2 ) dengan kondisi volume lalu lintas tersibuk terjadi pada pagi dan sore hari.
Ruas jalan merupakan ruang gerak lalu lintas yang menghubungkan antar zona lalu lintas. Dengan menggunakan Manual Kapasitas Jalan Indonesia (MKJI) Kinerja Ruas jalan eksisting pada ruas jalan Dipenegoro 1 dan ruas jalan Dipenegoro 2 dapat dijelaskan pada Tabel 3.

Tabel 3. Kinerja Ruas Jalan Wilayah Penelitian

\begin{tabular}{cclccccc}
\hline No & Segmen & \multicolumn{1}{c}{ Penggalan Jalan } & $\begin{array}{c}\text { Lebar } \\
(\mathrm{m})\end{array}$ & $\mathrm{C}$ & Volume & VCR & Ket. \\
\hline 1 & Segmen 1 & $\begin{array}{l}\text { md. Sp. Jl. Sudirman s/d } \\
\text { Sp. Jl. Z Arifin }\end{array}$ & 11 & 4144,44 & 2856,34 & 0,69 & $\mathrm{C}$ \\
\hline 2 & Segmen 2 & $\begin{array}{l}\text { md. Sp. Jl. Sudirman s/d } \\
\text { Sp. Jl. Kejaksaan }\end{array}$ & 12 & 4144,44 & 2128,4 & 0,51 & $\mathrm{C}$ \\
\hline
\end{tabular}

Sumber : Hasil Analisa, 2017

Pada tabel 3. di atas, penggal ruas jalan pada wilayah penelitian segmen 1 memiliki volume lalu lintas sebesar 2856,34 smp/jam dengan kapasitas ruas jalan sebesar 4144,44 smp/jam maka perbandingan volume kapasitas (VCR) sebesar 0.69 dengan indicator tingkat pelayanan C. Sedangkan pada segmen 2 volume lalu lintas sebesar 2128,4 smp/jam dengan kapasitas ruas jalan sebesar 4144,44 smp/jam, maka perbandingan volume kapasitas (VCR) sebesar 0.51 dengan indicator tingkat pelayanan $\mathrm{C}$.

\section{Pertumbuhan Volume Lalu lintas}

Untuk meramalkan jumlah perjalanan tahun perencanaan, sebelumnya harus diramalkan terlebih dahulu jumlah perjalanan masing-masing segmen. Jumlah perjalanan diasumsikan konstan untuk tahun rencana dan perkembangan jumlah perjalanan akan berganda dengan sendirinya.

$$
\text { Pt }=\text { Po }(1+i)^{n}
$$

\section{Sumber : Perencanaan dan Permodelan}

\section{Transportasi}

Dimana :

Pt : Jumlah perjalanan dimasa datang

Po: Jumlah perjalanan saat ini

i : Faktor pertumbuhan

$\mathrm{n}$ : Tahun perencanaan

Pertumbuhan rata-rata perjalanan adalah sebesar 9,61\% (Sumber: Dinas Perhubungan Kota Medan). Di bawah ini tabel faktor pertumbuhan dan peramalan perjalanan hingga tahun 2018 s/d 2021.

Tabel 4. Tingkat Pertumbuhan Kendaraan Pada Daerah Studi Tahun 2018

\begin{tabular}{|c|c|c|c|c|c|c|c|c|c|c|}
\hline \multirow[t]{2}{*}{ No. } & \multirow{2}{*}{ Waktu } & \multirow{2}{*}{ Segmen } & \multicolumn{2}{|c|}{$\begin{array}{l}\text { Jumlah Kend. } \\
\text { Pribadi }\end{array}$} & \multicolumn{2}{|c|}{$\begin{array}{l}\text { Jumlah Angk. } \\
\text { Umum }\end{array}$} & \multicolumn{2}{|c|}{$\begin{array}{l}\text { Jumlah Sepeda } \\
\text { Motor }\end{array}$} & \multicolumn{2}{|c|}{$\begin{array}{l}\text { Total Kend. } \\
\text { Bermotor }\end{array}$} \\
\hline & & & (kend/j) & $(\mathrm{smp} / \mathrm{j})$ & (kend/j) & $(\mathrm{smp} / \mathrm{j})$ & (kend/j) & $(\mathrm{smp} / \mathrm{j})$ & (kend/j) & $(\mathrm{smp} / \mathrm{j})$ \\
\hline 1 & $07.00-08.00$ & 1 & 1537 & 1537.3 & 237 & 236.6 & 3125 & 1249.9 & 4899 & 3023.9 \\
\hline 2 & 08.01-09.00 & 1 & 1552 & 1552.2 & 257 & 257.1 & 3164 & 1265.6 & 4973 & 3074.9 \\
\hline 3 & $11.00-12.00$ & 1 & 1470 & 1470.2 & 233 & 232.9 & 3088 & 1235.1 & 4791 & 2938.2 \\
\hline 4 & $12.01-13.00$ & 1 & 1500 & 1500 & 250 & 249.7 & 3110 & 1243.9 & 4860 & 2993.7 \\
\hline 5 & $16.00-17.00$ & 1 & 1573 & 1572.7 & 253 & 253.4 & 3171 & 1268.6 & 4998 & 3094.7 \\
\hline 6 & $17.01-18.00$ & 1 & 1593 & 1593.2 & 265 & 264.6 & 3183 & 1273.1 & 5040 & 3130.8 \\
\hline 7 & $07.00-08.00$ & 2 & 1133 & 1132.9 & 183 & 182.6 & 2339 & 935.4 & 3654 & 2251 \\
\hline 8 & 08.01-09.00 & 2 & 1155 & 1155.3 & 194 & 193.8 & 2353 & 941.3 & 3703 & 2290.5 \\
\hline 9 & $11.00-12.00$ & 2 & 1096 & 1095.7 & 177 & 177 & 2305 & 921.9 & 3578 & 2194.7 \\
\hline 10 & $12.01-13.00$ & 2 & 1109 & 1108.7 & 190 & 190.1 & 2320 & 927.9 & 3619 & 2226.7 \\
\hline 11 & $16.00-17.00$ & 2 & 1170 & 1170.2 & 199 & 199.4 & 2368 & 947.3 & 3738 & 2316.9 \\
\hline 12 & $17.01-18.00$ & 2 & 1183 & 1183.2 & 196 & 195.7 & 2385 & 954.1 & 3764 & 2332.9 \\
\hline
\end{tabular}


Sumber : Hasil Analisa, 2017

Tabel 5. Tingkat Pertumbuhan Kendaraan Pada Daerah Studi Tahun 2019

\begin{tabular}{|c|c|c|c|c|c|c|c|c|c|c|}
\hline \multirow{2}{*}{ No. } & \multirow{2}{*}{ Waktu } & \multirow{2}{*}{ Segmen } & \multicolumn{2}{|c|}{$\begin{array}{l}\text { Jumlah Kend. } \\
\text { Pribadi }\end{array}$} & \multicolumn{2}{|c|}{$\begin{array}{l}\text { Jumlah Angk. } \\
\text { Umum }\end{array}$} & \multicolumn{2}{|c|}{$\begin{array}{l}\text { Jumlah Sepeda } \\
\text { Motor }\end{array}$} & \multicolumn{2}{|c|}{$\begin{array}{l}\text { Total Kend. } \\
\text { Bermotor }\end{array}$} \\
\hline & & & (kend/j) & $(\mathrm{smp} / \mathrm{j})$ & (kend/j) & $(\mathrm{smp} / \mathrm{j})$ & (kend/j) & $(\mathrm{smp} / \mathrm{j})$ & (kend/j) & $(\mathrm{smp} / \mathrm{j})$ \\
\hline 1 & $07.00-08.00$ & 1 & 1685 & 1685 & 259 & 259.4 & 3425 & 1370.1 & 5370 & 3314.5 \\
\hline 2 & 08.01-09.00 & 1 & 1701 & 1701.4 & 282 & 281.9 & 3468 & 1387.2 & 5451 & 3370.4 \\
\hline 3 & $11.00-12.00$ & 1 & 1611 & 1611.5 & 255 & 255.3 & 3384 & 1353.7 & 5251 & 3220.5 \\
\hline 4 & $12.01-13.00$ & 1 & 1644 & 1644.2 & 274 & 273.7 & 3409 & 1363.5 & 5327 & 3281.4 \\
\hline 5 & $16.00-17.00$ & 1 & 1724 & 1723.8 & 278 & 277.8 & 3476 & 1390.5 & 5478 & 3392.1 \\
\hline 6 & $17.01-18.00$ & 1 & 1746 & 1746.3 & 290 & 290 & 3488 & 1395.4 & 5525 & 3431.7 \\
\hline 7 & $07.00-08.00$ & 2 & 1242 & 1241.8 & 200 & 200.2 & 2563 & 1025.3 & 4005 & 2467.3 \\
\hline 8 & 08.01-09.00 & 2 & 1266 & 1266.3 & 212 & 212.4 & 2580 & 1031.8 & 4058 & 2510.6 \\
\hline 9 & $11.00-12.00$ & 2 & 1201 & 1201 & 194 & 194 & 2526 & 1010.6 & 3921 & 2405.6 \\
\hline 10 & $12.01-13.00$ & 2 & 1215 & 1215.3 & 208 & 208.3 & 2543 & 1017.1 & 3966 & 2440.7 \\
\hline 11 & $16.00-17.00$ & 2 & 1283 & 1282.7 & 219 & 218.5 & 2596 & 1038.4 & 4097 & 2539.6 \\
\hline 12 & $17.01-18.00$ & 2 & 1297 & 1296.9 & 214 & 214.5 & 2614 & 1045.7 & 4126 & 2557.1 \\
\hline
\end{tabular}

Sumber : Hasil Analisa, 2017

Tabel 6. Tingkat Pertumbuhan Kendaraan Pada Daerah Studi Tahun 2020

\begin{tabular}{|c|c|c|c|c|c|c|c|c|c|c|}
\hline \multirow[t]{2}{*}{ No. } & \multirow[t]{2}{*}{ Waktu } & \multirow{2}{*}{ Segmen } & \multicolumn{2}{|c|}{$\begin{array}{l}\text { Jumlah Kend. } \\
\text { Pribadi }\end{array}$} & \multicolumn{2}{|c|}{$\begin{array}{l}\text { Jumlah Angk. } \\
\text { Umum }\end{array}$} & \multicolumn{2}{|c|}{$\begin{array}{l}\text { Jumlah Sepeda } \\
\text { Motor }\end{array}$} & \multicolumn{2}{|c|}{$\begin{array}{l}\text { Total Kend. } \\
\text { Bermotor }\end{array}$} \\
\hline & & & (kend/j) & $(\mathrm{smp} / \mathrm{j})$ & (kend/j) & $(\mathrm{smp} / \mathrm{j})$ & (kend/j) & $(\mathrm{smp} / \mathrm{j})$ & (kend/j) & $(\mathrm{smp} / \mathrm{j})$ \\
\hline 1 & $07.00-08.00$ & 1 & 1847 & 1846.9 & 284 & 284.3 & 3754 & 1501.7 & 5886 & 3633 \\
\hline 2 & 08.01-09.00 & 1 & 1865 & 1864.9 & 309 & 308.9 & 3801 & 1520.5 & 5975 & 3694.3 \\
\hline 3 & $11.00-12.00$ & 1 & 1766 & 1766.3 & 280 & 279.8 & 3710 & 1483.8 & 5756 & 3530 \\
\hline 4 & $12.01-13.00$ & 1 & 1802 & 1802.2 & 300 & 300 & 3736 & 1494.5 & 5839 & 3596.7 \\
\hline 5 & $16.00-17.00$ & 1 & 1889 & 1889.5 & 304 & 304.5 & 3810 & 1524.1 & 6004 & 3718.1 \\
\hline 6 & $17.01-18.00$ & 1 & 1914 & 1914.1 & 318 & 317.9 & 3824 & 1529.5 & 6056 & 3761.5 \\
\hline 7 & $07.00-08.00$ & 2 & 1361 & 1361.1 & 219 & 219.4 & 2810 & 1123.8 & 4390 & 2704.4 \\
\hline 8 & 08.01-09.00 & 2 & 1388 & 1388 & 233 & 232.8 & 2828 & 1131.1 & 4448 & 2751.8 \\
\hline 9 & $11.00-12.00$ & 2 & 1316 & 1316.4 & 213 & 212.7 & 2769 & 1107.7 & 4298 & 2636.8 \\
\hline 10 & $12.01-13.00$ & 2 & 1332 & 1332 & 228 & 228.3 & 2787 & 1114.8 & 4348 & 2675.3 \\
\hline 11 & $16.00-17.00$ & 2 & 1406 & 1405.9 & 240 & 239.5 & 2845 & 1138.2 & 4491 & 2783.6 \\
\hline 12 & $17.01-18.00$ & 2 & 1422 & 1421.6 & 235 & 235.1 & 2866 & 1146.2 & 4522 & 2802.9 \\
\hline
\end{tabular}

Sumber : Hasil Analisa, 2017

Tabel 7. Tingkat Pertumbuhan Kendaraan Pada Daerah Studi Tahun 2021

\begin{tabular}{|c|c|c|c|c|c|c|c|c|c|c|}
\hline \multirow[t]{2}{*}{ No. } & \multirow{2}{*}{ Waktu } & \multirow[t]{2}{*}{ Segmen } & \multicolumn{2}{|c|}{$\begin{array}{c}\text { Jumlah Kend. } \\
\text { Pribadi }\end{array}$} & \multicolumn{2}{|c|}{$\begin{array}{l}\text { Jumlah Angk. } \\
\text { Umum }\end{array}$} & \multicolumn{2}{|c|}{$\begin{array}{l}\text { Jumlah Sepeda } \\
\text { Motor }\end{array}$} & \multicolumn{2}{|c|}{$\begin{array}{c}\text { Total Kend. } \\
\text { Bermotor }\end{array}$} \\
\hline & & & (kend/j) & $(\mathrm{smp} / \mathrm{j})$ & (kend/j) & $(\mathrm{smp} / \mathrm{j})$ & (kend/j) & $(\mathrm{smp} / \mathrm{j})$ & (kend/j) & $(\mathrm{smp} / \mathrm{j})$ \\
\hline 1 & 07.00-08.00 & 1 & 2024 & 2024.4 & 312 & 311.6 & 4115 & 1646.1 & 6451 & 3982.1 \\
\hline 2 & 08.01-09.00 & 1 & 2044 & 2044.1 & 339 & 338.6 & 4167 & 1666.6 & 6549 & 4049.4 \\
\hline 3 & $11.00-12.00$ & 1 & 1936 & 1936.1 & 307 & 306.7 & 4066 & 1626.4 & 6309 & 3869.2 \\
\hline 4 & $12.01-13.00$ & 1 & 1975 & 1975.4 & 329 & 328.8 & 4095 & 1638.2 & 6400 & 3942.4 \\
\hline 5 & $16.00-17.00$ & 1 & 2071 & 2071.1 & 334 & 333.7 & 4176 & 1670.6 & 6581 & 4075.4 \\
\hline 6 & $17.01-18.00$ & 1 & 2098 & 2098 & 348 & 348.4 & 4191 & 1676.5 & 6638 & 4123 \\
\hline 7 & $07.00-08.00$ & 2 & 1492 & 1491.9 & 240 & 240.5 & 3080 & 1231.8 & 4812 & 2964.3 \\
\hline
\end{tabular}


Ashari, M, I, Nuril Mahda, R dan Kamaluddin, L (2019), Analisa Perencanaan Jalur Sepeda Motor Pada Kawasan Tertib Lalu Lintas Di Kota Medan

\begin{tabular}{ccccccccccc}
8 & $08.01-09.00$ & 2 & 1521 & 1521.4 & 255 & 255.2 & 3099 & 1239.7 & 4876 & 3016.3 \\
\hline 9 & $11.00-12.00$ & 2 & 1443 & 1442.9 & 233 & 233.1 & 3035 & 1214.2 & 4711 & 2890.2 \\
\hline 10 & $12.01-13.00$ & 2 & 1460 & 1460 & 250 & 250.3 & 3055 & 1222.1 & 4765 & 2932.4 \\
\hline 11 & $16.00-17.00$ & 2 & 1541 & 1541 & 263 & 262.6 & 3119 & 1247.5 & 4922 & 3051.1 \\
\hline 12 & $17.01-18.00$ & 2 & 1558 & 1558.2 & 258 & 257.7 & 3141 & 1256.4 & 4957 & 3072.2 \\
\hline
\end{tabular}

Sumber : Hasil Analisa, 2017

Dari hasil perhitungan dengan bantuan Manual Kapasitas Jalan Indonesia (MKJI) kondisi kinerja ruas jalan Dipenegoro baik segmen 1 maupun segmen 2 dapat diprediksi seperti table berikut,

Tabel 8. Tingkat Pertumbuhan dan kinerja ruas jalan hingga tahun 2021

\begin{tabular}{|c|c|c|c|c|c|c|c|c|c|c|c|c|c|}
\hline \multirow{2}{*}{ No } & \multirow{2}{*}{ Segmen } & \multicolumn{3}{|c|}{ Tahun 2018} & \multicolumn{3}{|c|}{ Tahun 2019} & \multicolumn{3}{|c|}{ Tahun 2020} & \multicolumn{3}{|c|}{ Tahun 2021} \\
\hline & & $\mathbf{v}$ & C & VCR & $\mathbf{v}$ & C & VCR & $\mathbf{v}$ & C & VCR & $\mathbf{v}$ & C & VCR \\
\hline 1 & Segmen 1 & 3131 & 4144 & 0.76 & 3432 & 4144 & 0.83 & 3761 & 4144 & 0.91 & 4123 & 4144 & 0.99 \\
\hline 2 & Segmen 2 & 2333 & 4144 & 0.56 & 2557 & 4144 & 0.62 & 2803 & 4144 & 0.68 & 3072 & 4144 & 0.74 \\
\hline
\end{tabular}

Sumber : Hasil Analisa, 2017

Dari tabel 8. di atas, dapat diketahui bahwa tingkat pertumbuhan perjalanan dalam jaringan kawasan penelitian terus semakin meningkat dari tahun-tahun sebelumnya. Dari analisis ini, diprediksi hingga tahun 2021 kawasan penelitian akan mengalami permasalahan lalu lintas yang cukup besar yaitu permasalahan kemacetan hal ini di karenakan dari hasil perhitungan gejala kemacatan ruas Jl. Pangeran Diponegoro sudah tidak dapat terkendali sepanjang tahun jika tidak ada langkah - langkah penanganan yang mengarah kepada peningkatan kinerja ruas jalan terutama dalam rangka menekan angka kecelakaan akibat berbaurnya kendaraan roda empat dengan roda dua, diantara penanganan tersebut adalah dengan membuat lajur khusus sepeda motor, lajur khusus angkutan umum dan penanggulangan hambatan samping terutara bagi kendaraan yang keluar dari dan ke area parkir.

\section{* Analisis Lajur Sepeda Motor}

Secara teori, kinerja ruas jalan dengan VCR mendekati 0,65 hampir setara dengan tingkat pelayanan jalan $\mathrm{C}$ yang berarti arus stabil tetapi kecepatan dan gerak kendaraan dikendalikan dan pengemudi dibatasi dalam memilih kecepatan, pindah lajur maupun mendahului. VCR dalam rentang $0,65 \leq$ VCR $\leq$ 0,85 sudah memasuki tingkat pelayanan jalan D yang berarti arus mendekati tidak stabil, kecepatan masih dikendalikan dan volume/kapasitasnya masih dapat ditolerir.
Dalam kondisi ini pengemudi sudah mengalami kesulitan di dalam kebebasan memilih kecepatan dan pindah lajur dan biasanya para kelompok pengemudi sepeda motor mulai memperlihatkan perilaku bermanuver yang tidak umum seperti menyiap atau memotong pergerakan lalu lintas secara ekstrim. Sedangkan nilai VCR sama dengan atau di atas 0,85 (VCR $\geq 0,85$ ) dinilai sudah mendekati nilai tingkat pelayanan jalan E. kondisi lalu lintas dalam rentang ini berarti sudah mendekati nilai kapasitas, sifat arus lalu lintas tidak stabil dan terjadi antrian. Pada kondisi seperti ini tidak ada kebebasan bagi pengemudi untuk memilih kecepatan dan bermanuver dalam arus lalu lintas dan mendorong kelompok pengemudi sepeda motor untuk melakukan maneuver manuver yang tidak umum, seperti mengisi celah-celah diantara lajur kendaraan bermotor roda empat dan perilaku memanfaatkan bahu jalan atau trotoar untuk dilalui yang cenderung makin memperparah kondisi lalu lintas.

Ruas jalan yang berada pada rentang $0,65 \leq$ VCR $\leq 0,85$ disarankan memerlukan lajur khusus sepeda motor yang digunakan bersama dengan kendaraan lain yang ditunjukkan dengan marka menerus sebagai pembatas lajur. Sedangkan untuk ruas jalan dengan VCR $\geq 0,85$ disarankan harus menggunakan lajur sepeda motor dengan menggunakan separator fisik sebagai pembatas lajur. 


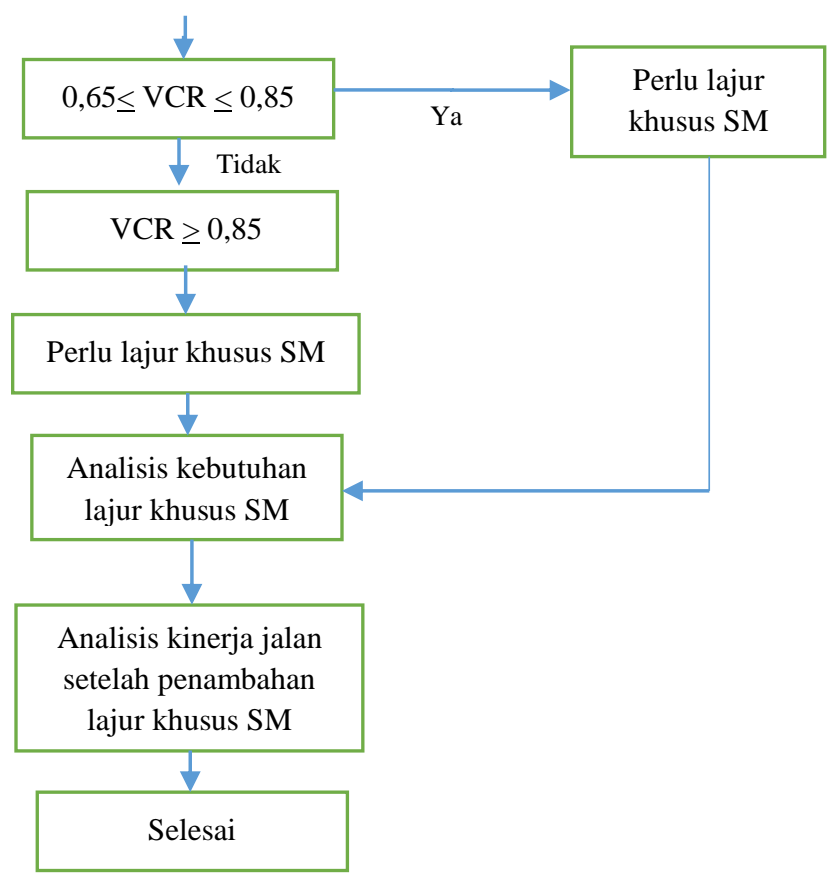

Gambar 5. Alur Kelayakan Lajur Khusus Sepeda Motor

Sumber : Balitbang Kota Medan

Analisis Kebutuhan Lajur Khusus Sepeda Motor

Dari data sebelumnya pada tahun 2018 direncanakan akan dioperasionalkan lajur khusus sepeda motor agar kemacetan pada ruas jalan Diponegoro yang berada di Kawasan Tertib Lalu Lintas dapat teratasi. Sehingga seluruh ruas jalan pada kawasan tersebut dapat secara efektif dan berhasil mengatasi peningkatan volume kendaraan yang terjadi setiap tahunnya.

Analisa kebutuhan lajur khusus sepeda motor berdasarkan hasil perhitungan kinerja ruas Jl. Pangeran Diponegoro, baik segmen 1 maupun segmen 2 terlihat pada table berikut,

Tabel 9. Kebutuhan Lajur Khusus Sepeda Motor

\begin{tabular}{|c|c|c|c|c|c|}
\hline Tahun & Segmen & Volume & C & VCR & Indikator \\
\hline \multirow{2}{*}{2017} & Segmen 1 & 2856.3 & 4144.1 & 0.69 & $\mathrm{C}$ \\
\hline & Segmen 2 & 2128.4 & 4144.1 & 0.51 & $\mathrm{C}$ \\
\hline \multirow{2}{*}{2018} & Segmen 1 & 3130.8 & 4144.1 & 0.76 & $\mathrm{D}$ \\
\hline & Segmen 2 & 2332.9 & 4144.1 & 0.56 & $\mathrm{C}$ \\
\hline \multirow{2}{*}{2019} & Segmen 1 & 3431.7 & 4144.1 & 0.83 & $\mathrm{D}$ \\
\hline & Segmen 2 & 2557.1 & 4144.1 & 0.62 & $\mathrm{C}$ \\
\hline \multirow{2}{*}{2020} & Segmen 1 & 3761.5 & 4144.1 & 0.91 & $\mathrm{E}$ \\
\hline & Segmen 2 & 2802.9 & 4144.1 & 0.68 & $\mathrm{C}$ \\
\hline \multirow{2}{*}{2021} & Segmen 1 & 4123.0 & 4144.1 & 0.99 & $E$ \\
\hline & Segmen 2 & 3072.2 & 4144.1 & 0.74 & $\mathrm{D}$ \\
\hline
\end{tabular}

Keterangan Indikator:

A = Kondisi arus lalu lintas dengan kecepatan tinggi dari volume lalu lintas rendah.
Pengemudi dapat memilih kecepatan yang diinginkan tanpa hambatan $(\mathrm{V} / \mathrm{C}=0,00-0,19)$ 
B = Dalam zona arus lalu lintas stabil. Pengemudi memiliki kebebasan yang cukup untuk memilih kecepatan $(\mathrm{V} / \mathrm{C}$ $=0,20-0,44)$

$\mathrm{C}=$ Dalam zona arus lalu lintas stabil. Pengemudi dibatasi dalam memilih kecepatannya $(\mathrm{V} / \mathrm{C}=0,45-0,74)$

$\mathrm{D}=$ Mendekati arus tidak stabil dimana hamper seluruh pengemudi akan dibatasi. Volume pelayanan berkaitan dengan kapasitas yang dapat ditolelir $(\mathrm{V} / \mathrm{C}=0,75-0,85)$

$\mathrm{E}=$ Volume arus lalu lintas mendekati atau berada pada kapasitasnya. Arus adalah tidak stabil dengan kondisi yang sering berhenti $(\mathrm{V} / \mathrm{C}=0,85$ $1,00)$

$\mathrm{F}=$ Kecepatan-kecepatan yang rendah. Antrian yang panjang dan terjadi hambatanhambatan yang besar $(\mathrm{V} / \mathrm{C}=>1,00)$

Oleh karena itu, dari hasil pengolahan data di atas diketahui bahwa ruas Jl. Pangeran Diponegoro 1 (segmen 1) di tahun 2017 sudah harus dibangun lajur khusus sepeda motor hal ini dikarenakan nilai $\mathrm{V} / \mathrm{C}$ ratio sebesar 0,69 dengan indicator pelayanan $\mathrm{C}$ dengan lajur khusus menggunakan marka menerus sedangkan untuk ruas Jl. Pangeran Diponegoro 2 (segmen 2) baru dibangun lajur khusus sepeda motor pada tahun 2019 hal ini dikarenakan bahwa, tahun 2019 nilai V/C ratio nya sebesar 0,62 dengan indicator pelayanan $\mathrm{C}$.

Pada tahun 2020 perlu dilakukan peningkatan lajur khusus sepeda motor dari lajur khusus marka menerus menjadi lajur khusus dengan pembatan separator atau median terutama pada ruas Jl. Pangeran Diponegoro 1 ( segmen 1 ), hal ini dikarenakan pada ruas jalan tersebut terjadi peningkatan nilai $\mathrm{V} / \mathrm{C}$ ratio menjadi 0,91 dengan indicator pelayanan E, sedangkan untuk ruas Jl. Pangeran Diponegoro 2 masih dapat dipertahankan menggunakan lajur khusus sepeda motor marka menerus, hal ini dikarenakan nilai $\mathrm{V} / \mathrm{C}$ rationya sebesar 0,68 dengan indicator pelayanan masih $\mathrm{C}$.

Pada tahun 2021 perlu dilakukan peningkatan lajur khusus sepeda motor dari lajur khusus marka menerus menjadi lajur khusus dengan pembatan separator atau median pada ruas Jl. Pangeran Diponegoro 2 ( segmen 2 ), hal ini dikarenakan pada ruas jalan tersebut terjadi peningkatan nilai $\mathrm{V} / \mathrm{C}$ ratio menjadi 0,74 dengan indicator pelayanan D, sedangkan untuk ruas Jl. Pangeran Diponegoro 1 masih dapat dipertahankan menggunakan lajur khusus sepeda motor seperti sebelumnya hanya saja perlu dilakukan evaluasi guna meningkatkan kinerja pada ruas Jl. Pangeran Diponegoro 1, hal ini dikarenakan nilai $\mathrm{V} / \mathrm{C}$ rationya sudah sebesar 0,99 dengan indicator pelayanan masih $\mathrm{E}$.

\section{Analisa sesudah Adanya Lajur Khusus Sepeda Motor}

Dari hasil evaluasi dan analisa data terhadap ruas Jl. Pangeran Diponegoro 1 (segmen 1) dan Jl. Pangeran Diponegoro 2 ( segmen2) di ketahui bahwa pembangunan lajur khusus sepeda motor seharusnya sudah mulai dilaksanakan sejak tahun 2017 terutama pada ruas segmen 1dan barulah tahun 2019 di bangun lajur khusus sepeda motor untuk segmen 2 dengan pembatas marka menerus.Tahun 2020 dan tahun 2021 seluruh segmen harus dipasang separator sebagai pembatas lajur khusus sepeda motor untuk segmen 1 dan segmen 2 .

Selanjutnya bagai mana kinerja ruas jalan masing - masing lajursetelah di bangunnya pembatas lajur khusus sepeda motor pada ruas Jl. Pangeran Diponegoro baik segmen 1 maupun segmen 2, dengan menggunkan Manual Kapasitas Jalan Indonesia (MKJI) dapat di hitung kinerja masing masing lajur dan hasilnya dapat dilihat pada tabel berikut.

Tabel 10. Kinerja Ruas Jalan Khusus Roda Empat

\begin{tabular}{|c|c|c|c|c|c|}
\hline Tahun & Segmen & Volume & C & VCR & Indikator \\
\hline \multirow{2}{*}{2017} & Segmen 1 & 1694.9 & 4144.1 & 0.61 & $\mathrm{C}$ \\
\hline & Segmen 2 & 1258.0 & 4144.1 & 0.46 & $\mathrm{C}$ \\
\hline \multirow{2}{*}{2018} & Segmen 1 & 1857.8 & 4144.1 & 0.67 & $\mathrm{C}$ \\
\hline & Segmen 2 & 1378.9 & 4144.1 & 0.50 & $\mathrm{C}$ \\
\hline \multirow{2}{*}{2019} & Segmen 1 & 2036.3 & 4144.1 & 0.74 & D \\
\hline & Segmen 2 & 1511.4 & 4144.1 & 0.55 & $\mathrm{C}$ \\
\hline
\end{tabular}




\begin{tabular}{llllll}
\multirow{2}{*}{2020} & Segmen 1 & 2232.0 & 4144.1 & 0.81 & D \\
\cline { 2 - 6 } & Segmen 2 & 1656.7 & 4144.1 & 0.60 & $\mathrm{C}$ \\
\hline \multirow{2}{*}{2021} & Segmen 1 & 2446.5 & 4144.1 & 0.89 & E \\
\cline { 2 - 6 } & Segmen 2 & 1815.9 & 4144.1 & 0.66 & $\mathrm{C}$ \\
\hline
\end{tabular}

Sumber : Hasil Analisa, 2017

Tabel 11. Kinerja Ruas Jalan Khusus Sepeda Motor

\begin{tabular}{cccccc}
\hline Tahun & Segmen & Volume & C & VCR & Indikator \\
\hline \multirow{2}{*}{2017} & Segmen 1 & 1161.4 & 2762.8 & 0.42 & B \\
\cline { 2 - 6 } & Segmen 2 & 870.4 & 2762.8 & 0.32 & B \\
\hline \multirow{2}{*}{2018} & Segmen 1 & 1273.1 & 2762.8 & 0.46 & $\mathrm{C}$ \\
\cline { 2 - 6 } & Segmen 2 & 954.0 & 2762.8 & 0.35 & $\mathrm{~B}$ \\
\hline \multirow{2}{*}{2019} & Segmen 1 & 1395.4 & 2762.8 & 0.51 & $\mathrm{C}$ \\
\cline { 2 - 6 } & Segmen 2 & 1045.7 & 2762.8 & 0.38 & $\mathrm{~B}$ \\
\hline \multirow{2}{*}{2020} & Segmen 1 & 1529.5 & 2762.8 & 0.55 & $\mathrm{C}$ \\
\cline { 2 - 6 } & Segmen 2 & 1146.2 & 2762.8 & 0.41 & $\mathrm{~B}$ \\
\hline \multirow{2}{*}{2021} & Segmen 1 & 1676.5 & 2762.8 & 0.61 & $\mathrm{C}$ \\
\cline { 2 - 6 } & Segmen 2 & 1256.4 & 2762.8 & 0.45 & $\mathrm{C}$ \\
\hline
\end{tabular}

Sumber : Hasil Analisa, 2017

Dari table 10 dan 11 di atas dapat dilihat bahwa pembangunan lajur khusus sepeda motor di ruas Jl. Pangeran Diponegoro baik segmen 1 maupun segmen 2 sangat berarti dalam rangka menjaga kinerja ruas jalan tersebut hal ini terlihat bahwa dengan adanya lajur khusus Sepeda motor lajur khusus roda empat tidak mengalami penurunan kinerja bahkan meningkatkan kinerja hingga $20 \%$ dari sebelumnya. Begitu juga halnya dengan lajur khusus Sepeda motor hingga tahun 2021 tidak mengalami penurunan kinerja dengan indicator rata-rata B ke C.

\section{SIMPULAN}

Berdasarkan hasil analisa yang dilakukan, maka harus segera dibangun jalur khusus sepeda motor agar kinerja diruas Jl. Pangeran Diponegoro meningkat dan kajian ini memperlihatkan bahwa terdapat korelasi yang signifikan antara pertumbuhan sepeda motor terhadap kinerja ruas jalan, dalam hal ini diperlihatkan oleh indicator menurunnya kecepatan operasional lalu lintas dan peningkatan tingkat kinerja jalan. Dari analisis yang telah dilakukan, dapat disimpulkan beberapa hal yang dapat dijadikan pedoman untuk mengetahui kinerja ruas Jl. Pangeran Diponegoro terhadap perencanaan jalur khusus sepeda motor di Kota Medan, Antara lain:

Ruas jalan pada wilayah penelitian segmen 1 memiliki volume lalu lintas sebesar 2856,34 smp/jam dengan kapasitas ruas jalan sebesar 4144,44 $\mathrm{smp} /$ jam maka perbandingan volume kapasitas (VCR) sebesar 0.69 dengan indicator tingkat pelayanan C. Ruas pada segmen 2 volume lalulintassebesar 2128,4 smp/jam dengankapasitasruasjalansebesar 4144,44 smp/jam, makaperbandingan volume kapasitas (VCR) sebesar 0.51 dengan indicator tingkat pelayanan $\mathrm{C}$.

Ruas jalan segmen 1 di tahun 2017 sudah harus dibangun lajur khusus sepeda motor hal ini dikarenakan nilai $\mathrm{V} / \mathrm{C}$ ratio sebesar 0,69 dengan indicator pelayanan $\mathrm{C}$ dengan lajur khusus menggunakan marka menerus sedangkan untuk ruas jalan segmen 2 baru dibangun lajur khusus sepeda motor pada tahun 2019 hal ini dikarenakan bahwa , tahun 2019 nilai 
$\mathrm{V} / \mathrm{C}$ ratio nya sebesar 0,62 dengan indicator pelayanan $\mathrm{C}$.

* Pada tahun 2020 perlu dilakukan peningkatan lajur khusus sepeda motor dari lajur khusus marka menerus menjadi lajur khusus dengan pembatas separator atau median terutama pada ruas jalan segmen 1 , halinidikarenakanpadaruasjalanterseb utterjadipeningkatannilai $\mathrm{V} / \mathrm{C}$ ratio menjadi 0,91 dengan indicator pelayanan $\mathrm{E}$, sedangkan untuk ruas jalan segmen 2 masih dapat dipertahankan menggunakan lajur khusus sepeda motor marka menerus, hal ini dikarenakan nilai V/C rationya sebesar 0,68 dengan indicator pelayanan masih C.

* Pada tahun 2021 perlu dilakukan peningkatan lajur khusus sepeda motor dari lajur khusus marka menerus menjadi lajur khusus dengan pembatas separator atau median pada ruas jalan segmen 2, hal ini dikarenakan pada ruas jalan tersebut terjadi peningkatan nilai $\mathrm{V} / \mathrm{C}$ ratio menjadi 0,74 dengan indicator pelayanan $\mathrm{D}$, sedangkan untuk ruas jalan segmen 1 masih dapat dipertahankan menggunakan laju khusus sepeda motor seperti sebelumnya hanya saja perlu dilakukan evaluasi guna meningkatkan kinerja pada ruas jalan segmen 1 , hal ini dikarenakan nilai $\mathrm{V} / \mathrm{C}$ rationya sudah sebesar 0,99 dengan indicator pelayanan masih E.

* Diperlukan adanya peran aktif pemerintah dalam upaya peningkatan kualitas kinerja ruas jalan pada Kawasan Tertib Lalu Lintas khususnya pada Jl. Pangeran Diponegoro;

* Diperlukan adanya Transport Demand Management (TDM) yang handal karena perbaikan transportasi tidak cukup dengan melebarkan jalan atau hal-hal lain yang bersifat fisik;

* Beberapa saran berkaitan dengan penetapan lajur khusus sepeda motor, antara lain masih diperlukan kajian yang lebih luas terhadap kinerja ruasruas jalan.

\section{DAFTAR PUSTAKA}

Adriyana, D. (2011), "Studi Fenomena Pertumbuhan Penggunaan Moda Sepeda Motor di Kota Bandung (Studi Kasus: Koridor Jalan Abdul Haris Nasution)", Tugas Akhir, Institut Teknologi Bandung, Bandung.

Anonimus, (1997), "Manual Kapasitas Jalan Indonesia (MKJI)", Departemen Pekerjaan Umum Direktorat Jendral Bina Marga, Jakarta.

Arizudin, F., (2004). "Sepeda motor sebagai solusi transportasi masa kini". (http://ekonomi.kompasiana.com/m anajemen/2012/01/13/sepedamotor-sebagai-solusi transportasimasa-kini benarkah/), (Online) di akses 18 maret 2012.

Hai, P.K. dan Susilo, Y.O., (2009), "The Motorcycle Ownership Behaviour in Hanoi City, Vietnam:How Unique They are Compare to Other Countries?", Proceeding of the Eastern Asia Society for TransportationStudies, Vol. 7.

Hsu, T.P., Sadullah, A.F.M., dan Dao, N.X., (2003), "A Comparison Study on Motorcycle Traffic Development in Some Asian Countries-Case of Taiwan,Malaysia, and

Vietnam",(http://www.easts.info/act ivities/icra/2001-Comparison Study Motorcycle Development.pdf, diakses 3 April 2012).

Joewono, T.B. (2010), “ Pengembangan Psikologi Lalu Lintas dalam manajemen Lalu Lintas Perkotaan di Indonesia ", Laporan Hibah Kompetensi tahun ke dua, Bandung.

Lubis, H.A.R.S., (2009), "Motorcycle Growth and Its Impacts to Urban Transportation.", Proceeding of the Eastern Asia Society for Transportation Studies, Vol. 7.

Pusat Bahasa., (2008) "Kamus Besar Bahasa Indonesia" , Edisi Keempat, PT. Gramedia Pustaka Utama, Jakarta.

Senbil, M., Zhang, J. dan Fujiwara, A., (2006),"Motorcycle Ownership and Use In Jabotabek(Indonesia)MetropolitanAr $e a "$, Discussion Paper Series, Graduate School of International Development And Cooperation, Hiroshima University,Vol. 3. 
Tamin, O.Z., (2000),"Perencanaan dan Permodelan Transportasi",Edisi

Kedua, Institut Teknologi Bandung.

Taylor, M.A.P., and Prabnasak, J., (2008), "Study on Mode Choice and Vehicle Ownership in a Medium-Sized Asian City", The 30thConference of Austalian Institutes of Transport Research Proceedings (CAITR2008 Proccedings), University of Western Australia, Perth.

Tuan, V.A. dan Shimizu, T., (2005), "Modeling of Household Motorcycle Ownership Behavior In Hanoi City", Journal of the Eastern Asia Society for Transportation Studies, Vol. 6. 